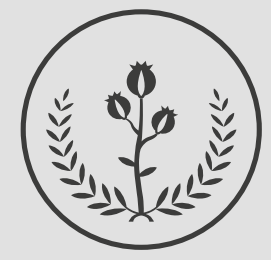

FUCS

\title{
Cobertura de vacunación contra COVID -19 por esquema en Colombia
}

Jorge Enrique Díaz-Pinzón ${ }^{a}$

\section{Covid-19 vaccination coverage by regime in Colombia}

a Ingeniero. Magister en Gestión de la Tecnología Educativa, Especialista en Administración de la Informática Educativa.

Docente de matemáticas e Investigador, Secretaría de Educación de Soacha, Cundinamarca.

\section{R E S U M EN}

Introducción: una de las principales dificultades en el desarrollo temprano de las vacunas contra el coronavirus del SARS ha sido el hallazgo de inmunopotenciación no esperada en forma de infiltración eosinofílica o aumento de la infectividad, que ocurre después de infecciones de provocación, inmunizaciones con vacunas de virus completos o de proteína de pico completo. Objetivo: exhibir el avance de la cobertura de vacunación contra el COVID-19 por esquema en las entidades territoriales de Colombia en el periodo comprendido entre el 17 de febrero al 26 de agosto 2021. Metodología: estudio de tipo transversal analítico diseñado para recoger información sobre vacunas administradas en Colombia por esquema de vacunación; la fuente de información fue del plan nacional de vacunación contra el COVID-19 de la página web del Ministerio de Salud y Protección Social. Resultados: se estableció que al 26 de agosto 2021 las entidades territoriales con mayor número de cobertura por esquema fueron: San Andrés y Providencia, Amazonas, Quindío, Boyacá y Tolima y las de menor número de cobertura por esquema fueron: Vichada, Chocó, Guajira, Putumayo y Cundinamarca. Conclusión: es una imperiosa necesidad de seguridad nacional promover y almacenar vacunas contra el coronavirus y establecer mecanismos de financiación a nivel internacional para avalar su desarrollo, fabricación y almacenamiento.

Palabras clave: COVID-19, SARS-COV-2, pandemia, vacunas.

(C) 2021 Fundación Universitaria de Ciencias de la Salud - FUCS. Este es un artículo Open Access bajo la licencia CC BY-NC-ND (http://creativecommons.org/licenses/by-nc-nd/4.0/).

\section{INFORMACIÓN DEL ARTÍCULO}

Historia del artículo:

Fecha recibido: septiembre 1 de 2021 Fecha aceptado: septiembre 22 de 2021

\footnotetext{
Autor para correspondencia.

Jorge Enrique Díaz Pinzón jediazp@unal.edu.co
}

DOI

10.31260/RepertMedCir.01217372.1280 
Introduction: one of the main difficulties in the early development of vaccines against SARS coronavirus has been finding an unexpected eosinophil-associated immunopotentiation or increased infectivity, that occurs following provocation infections and immunization with whole virus vaccines or full-length spike protein vaccines. Objective: to describe the progress of COVID-19 vaccination coverage by vaccination regime in the territorial entities of Colombia from February 17 to August 2021. Methodology: an analytical cross-sectional study designed to gather information on administered vaccines in Colombia by vaccination regime. Data was obtained from the Ministry of Health and Social Protection webpage based on the national vaccination plan. Results: as of August 26, 2021 the territorial entities with the most vaccination coverage by vaccination regime were: San Andres and Providencia, Amazonas, Quindío, Boyacá and Tolima and those with the lowest coverage by vaccination regime were: Vichada, Choco, Guajira, Putumayo and Cundinamarca. Conclusion ensuring national safety through coronavirus vaccine promotion and storage, establishing financial support mechanisms at the international level to endorse vaccine development, manufacturing and storage, is imperative.

Key words: COVID-19, SARS-COV-2, pandemic, vaccines.

(C) 2021 Fundación Universitaria de Ciencias de la Salud - FUCS. This is an open access article under the CC BY-NC-ND license (http://creativecommons.org/licenses/by-nc-nd/4.0/).

IN TRODUCCIÓN

Una de las principales dificultades para la obtención temprana de las vacunas contra el coronavirus del SARS ha sido la inmunopotenciación no esperada en forma de infiltración eosinofílica o aumento de la infectividad, observada después de infecciones de provocación, inmunizaciones con vacunas de virus completos de proteína de pico completo. ${ }^{1}$ Otro elemento importante de una vacuna TPP contra el SARS-COV o el SARS-COV-2 es la población objetivo-prevista. Al presente, las personas con mayor riesgo de contraer COVID-19 o de sufrir un deterioro significativo de la salud son los trabajadores sanitarios de primera línea, los mayores de 60 años o las personas con diabetes e hipertensión subyacentes. ${ }^{2}$ En consecuencia esta población podrían tener prioridad para los ensayos clínicos de vacunas o su autorización.

Otra característica es la posibilidad real de que una nueva vacuna para COVID-19 no esté disponible a tiempo para esta epidemia o pandemia para un posible almacenamiento. En ese sentido, las vacunas desarrolladas y producidas para la seguridad sanitaria mundial o la biodefensa a menudo se consideran menos rentables que las vacunas tradicionales para niños y adultos. Por esa razón muy pocas compañías farmacéuticas multinacionales parecen haber expresado un interés comercial directo para ingresar a este espacio. ${ }^{3}$

Las vacunas de virus completos vivos, atenuados o inactivos, incorporan una estrategia clásica para las vacunaciones virales. Según un boletín de la industria Johnson \& Johnson, es una de las pocas empresas multinacionales que se almacenan en las vacunas COVID-19. ${ }^{4}$

Además, investigadores de la Universidad de Hong Kong han desarrollado una vacuna viva contra la influenza que expresa proteínas del SARS-COV-2. ${ }^{5}$ Codagenix ha desarrollado una tecnología de "desoptimización de codones" para atenuar los virus y está explorando estrategias de vacunación contra el SARS-COV- $2 .{ }^{6}$

Las vacunas de subunidades para ambos coronavirus del SARS se basan en inducir una respuesta inmune contra la proteína S-spike para evitar su acoplamiento con el receptor ACE2 del huésped. ${ }^{1}$ Con fondos de la Coalition for Epidemic Preparedness (CEPI) la Universidad de Queensland ya está sintetizando proteínas de superficie viral para presentarlas más fácilmente al sistema inmunológico.

Asimismo, Novavax ha desarrollado y producido nanopartículas inmunogénicas similares a virus basadas en la expresión recombinante de la proteína $\mathrm{S}^{7}$, mientras que Clover Biopharmaceuticals está desarrollando una vacuna de subunidad que consiste en una proteína $S$ trimerizada del SARS-CoV-2, manejando su etiqueta Trimer-Tag patentada. ${ }^{8}$

En consecuencia, un consorcio liderado por el Texas Children's Hospital Center for Vaccine Development en Baylor College of Medicine (que incluye University of Texas Medical Branch y New York Blood Center) ha perfeccionado y probado una vacuna de subunidad compuesta solo por el dominio de unión al receptor (RBD) de la proteína $\mathrm{S}$ del SARS-CoV. ${ }^{9-11}$ Cuando se formula sobre alumbre, la vacuna SARS-COV RBD provoca altos niveles de inmunidad protectora en la exposición al virus homólogo. El objetivo de esta investigación es exhibir el avance de cobertura de vacunación contra COVID-19 por esquema en las entidades territoriales de Colombia en el periodo comprendido entre el 17 de febrero al 26 de agosto 2021. 


\section{METODOLOGÍA}

Estudio de tipo transversal analítico diseñado específico para recoger información sobre vacunas administradas en Colombia. Como fuente de información se tomó el plan nacional de vacunación contra el COVID-19 de la página web del Ministerio de Salud y Protección Social ${ }^{12}$, en el periodo comprendido entre el 17 de febrero 2021 a 26 de agosto 2021 . Se manejaron medios matemáticos y estadísticos cotidianos para valorar los resultados de modo evidente. ${ }^{13-15}$

\section{RESULTA D OS}

En la figura 1 podemos apreciar los valores de cobertura por esquema en las diferentes entidades territoriales de Colombia al 26 de agosto 2021. Se puede inferir que las entidades territoriales con mayor número de cobertura por esquema son: San Andrés y Providencia, Amazonas, Quindío, Boyacá y Tolima y las de menor: Vichada, Chocó, Guajira, Putumayo y Cundinamarca.

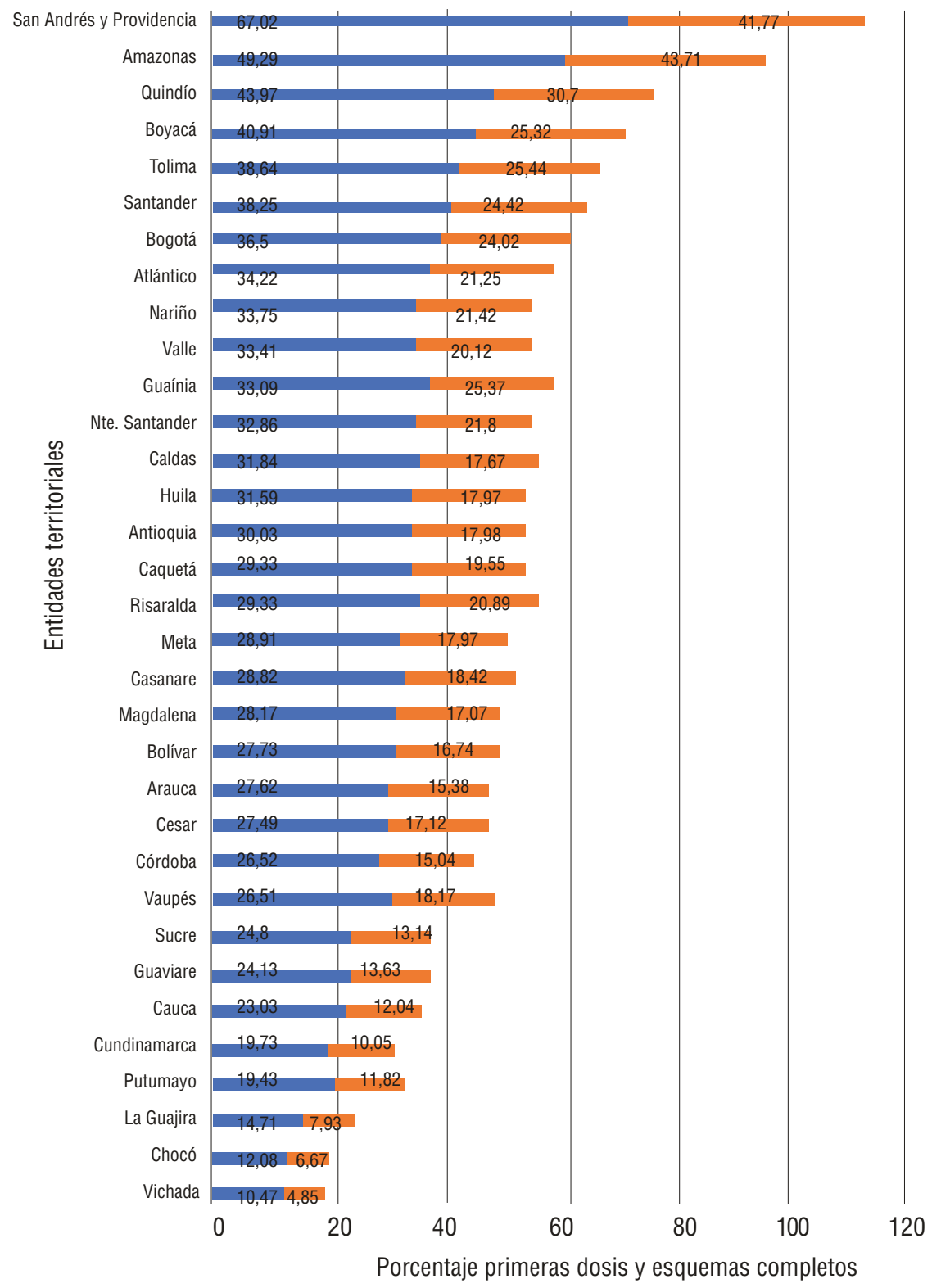

Fuente: el autor Primeras dosis Esquema completo

Figura 1. Porcentajes de esquemas completos por entidades territoriales 


\section{CONCLUSIONES}

Se estableció que al 26 de agosto 2021 las entidades territoriales con mayor número de cobertura por esquema de vacunación fueron: San Andrés y Providencia, Amazonas, Quindío, Boyacá y Tolima y las de menor número son: Vichada, Chocó, Guajira, Putumayo y Cundinamarca. Es imperioso promover y almacenar vacunas contra el coronavirus y establecer mecanismos de financiación a nivel internacional para avalar su desarrollo, fabricación y almacenamiento.

\section{DECLARACIÓN CONFLICTO} DE INTERESES

El autor declara no tener ningún tipo de conflicto de interés.

\section{REFEREN CI AS}

1. Jiang S, Bottazzi ME, Du L, Lustigman S, Tseng CT, Curti E, et al. Roadmap to developing a recombinant coronavirus $S$ protein receptor-binding domain vaccine for severe acute respiratory syndrome. Expert Rev Vaccines. 2012;11(12):1405-13. https://doi. org/10.1586/erv.12.126

2. Huang C, Wang Y, Li X, Ren L, Zhao J, Hu Y, et al. Clinical features of patients infected with 2019 novel coronavirus in Wuhan, China. Lancet. 2020;395(10223):497-506. https://doi.org/10.1016/S01406736(20)30183-5

3. Chen WH, Strych U, Hotez PJ, Bottazzi ME. El proceso de vacunación contra el SARS-CoV-2: una descripción general. Curr Trop Med Rep. 2020;1-4. https://doi.org/10.1007/s40475-020-00201-6

4. Thepharmaletter. J\&J working on coronavirus vaccine [Internet]. Thepharmaletter; 2020 [citado julio de 2021]. Disponible en: https://www.thepharmaletter.com/article/ j-j-working-on-coronavirus-vaccine

5. Cheung E. China coronavirus: Hong Kong researchers have already developed vaccine but need time to test it, expert reveals [Internet]. South China Morning Post; 2020 [citado julio de 2021]. Disponible en: https://www.scmp.com/comment/ opinion/article/3150152/china-joining-pacific-trade-pactwould-benefit-all-members-gaining module=perpetual_ scroll\&pgtype $=$ article $\&$ campaign $=3150152$
6. Shieber J. Codagenix raises $\$ 20$ million for a new flu vaccine and other therapies [Internet]. Join TechCrunch; 2020 [citado julio de 2021]. Disponible en: https://techcrunch. com/2020/01/13/codagenix-raises-20-million-for-a-newflu-vaccine-and-other-therapies/

7. Chen WH, Chag SM, Poongavanam MV, Biter AB, Ewere EA, Rezende $\mathrm{W}$, et al. Optimización del proceso de producción y caracterización del dominio de unión al receptor recombinante del SARS-CoV expresado en levadura (RBD219-N1), un candidato a vacuna contra el SARS. J Pharm Sci. 2017; 106 (8): 1961-70. https://doi.org/10.1016/j.xphs.2017.04.037

8. Biofarmacéuticos Clover. Clover inicia el desarrollo de una vacuna recombinante de subunidad-trímero para el coronavirus de Wuhan (2019-nCoV). 2020.

9. ClinicalTrials.gov. Institutos Nacionales de Salud. https:// clinicaltrials.gov/ct2/show/NCT02543567 .

10. Chen WH, Du L, Chag SM, Ma C, Tricoche N, Tao X, et al. Proteína recombinante expresada en levadura del dominio de unión al receptor en la proteína de pico de SARS-CoV con formas desglicosiladas como candidata a vacuna contra el SARS. Hum Vaccines Immunother. 2014; 10 (3): 648-58.

11. Coleman CM, Liu YV, Mu H, Taylor JK, Massare M, Flyer DC, et al. Las nanopartículas de proteína de pico de coronavirus purificadas inducen anticuerpos neutralizantes de coronavirus en ratones. Vacuna. 2014; 32 (26): 3169-74. https://doi.org/10.1016/j. vaccine.2014.04.016 .

12. Ministerio de Salud y Protección Social de Colombia. Plan de vacunación nacional contra COVID-19. Disponible en: https:// www.minsalud.gov.co/salud/publica/Vacunacion/Paginas/ Vacunacion-covid-19.aspx

13. Díaz Pinzón, J. E. (2020). Estimación de la prevalencia del COVID-19 en Colombia. Revista Repertorio De Medicina Y Cirugía, 99-102. https://doi.org/10.31260/RepertMedCir.01217372.1115

14. Díaz Pinzón, J. E. (2020). Análisis de los resultados del contagio del COVID-19 respecto a su distribución geográfica en Colombia. Revista Repertorio De Medicina Y Cirugía, 60-64. https://doi. org/10.31260/RepertMedCir.01217372.1082

15. Díaz Pinzón, J. E. (2021). Dinámica y relación del contagio del COVID-19 después de iniciado el plan de vacunación contra el SARS-COV-2 en Colombia. Revista Repertorio De Medicina Y Cirugía, 41-45. https://doi.org/10.31260/RepertM 